\title{
Erratum to: Mindfulness as a Building Block for Servant Leadership
}

\section{Armin Pircher Verdorfer and Johannes Arendt}

\section{Erratum to:}

(C) The Author(s) 2018

D. van Dierendonck, K. Patterson (eds.), Practicing Servant Leadership, https://doi.org/10.1007/978-3-319-75644-8_7

This chapter was inadvertently published with error in the author's name and the same has been updated.

A. P. Verdorfer

TUM School of Management, Technical University of Munich,

Munich, Germany.

J. Arendt

Department of Psychology, University of Munich, Munich, Germany

The updated original version of this chapter can be found at https://doi.org/10.1007/978-3-319-75644-8_7 